\title{
Regional sustainability assessment using emergy accounting approach: The case of Nepal in South Asia
}

\author{
Keshab Shrestha ${ }^{1}$, Izhar Hussain Shah ${ }^{2}$, Zhe Liu ${ }^{3}$, Hung-Suck Park ${ }^{1^{\dagger}}$ \\ ${ }^{1}$ Department of Civil and Environmental Engineering, University of Ulsan, Daehak-ro 93, Nam-gu, Ulsan 680-749, Republic of Korea \\ ${ }^{2}$ Department of Civil and Environmental Engineering, Imperial College London, Skempton Building, London SW7 2AZ, United Kingdom \\ ${ }^{3}$ Institute for Population and Development Studies, School of Public Policy and Administration, Xi'an Jiaotong University, Shaanxi Province 710049, \\ PR China
}

\begin{abstract}
Emergy accounting is an environmental assessment tool that accounts for all the energy pathways in production systems. In this regard, the System Thinking Experimental Learning Laboratory Animation (STELLA) with emergy model are used for a retrospective and prospective assessments. Nepal, a country having a relatively small economy but with faster recent growth as well as its geographical position and potentially high vulnerability to climate change was analyzed as a case study using data for 1998-2015 (retrospective) and 2015-2040 (prospective). As per our results, the rising use of non-renewable resources and decreasing use of locally extracted materials caused higher environmental load and reduced emergy sustainability scores. In addition, the effect of natural disasters, such as the Gorkha earthquake, on environmental performance of Nepal was analyzed by emergy accounting. Futuristic emergy analysis for 2015-2040 showed that total and non-renewable emergy would rise considerably, and the emergy sustainability index could further decrease by 33\%. Based on these findings, small yet rapidly growing economies, such as Nepal, could improve their environmental management by reducing the material trade deficit (i.e., by increasing domestic material extraction and reducing imports of non-renewable resources), minimizing the use of non-renewables, improving soil fertility, and promoting renewable resource consumption.
\end{abstract}

Keywords: Emergy accounting, Hybrid model, Nepal, STELLA modeling, Sustainability assessment

\section{Introduction}

The momentum for sustainability - which relies on a multifaceted approach encompassing economy, society, and the environment - has gained wider recognition globally [1, 2]. The need for sustainable development arises as human pressures on the environment, in terms of depletion of limited resources and waste generation, have reached alarming levels in the recent times [3, 4]. With socio-economic considerations and activities impacting the natural environment, assessing the sustainability of production systems has become a pivotal policy instrument throughout the world [5, 6]. In this context, sustainability assessments integrate the social, environmental, and economic perspectives into decision making and implementation through analytical tools and methodologies $[7,8]$, thus, capturing the essence of shared prosperity with long-term implications [9].

Sustainability assessments have become mainstream and a key component to quantitatively assess progress on the sustainable development goals (SDGs) [10]. In this regard, diverse methodologies have been proposed and developed in the previous decades such as the material flow analysis (analyzing the flow of resources and waste emissions), life cycle assessment (analyzing the environmental impacts of products and services from extraction to final disposal), ecological footprint analysis (analyzing the quantity of support taken from nature by people or an economy), input-output analysis (analyzing flows in production and economic systems using monetary dimensions), etc. The robustness and wide acceptability of several sustainability assessment approaches have been well documented [11-13]. Among different sustainability assessment methodologies, "emergy" accounting has emerged as a useful tool to measure the sustainability of complex production systems at varying scales [14, 15].

Among various sustainability assessment approaches, emergy accounting has gained popularity for several reasons. For instance,
This is an Open Access article distributed under the terms of the Creative Commons Attribution Non-Commercial License (http://creativecommons.org/licenses/by-nc/3.0/) which permits unrestricted non-commercial use, distribution, and reproduction in any medium, provided the original work is properly cited.

Copyright (C) 2022 Korean Society of Environmental Engineers
Received July 13, 2021 Accepted October 18, 2021

${ }^{\dagger}$ Corresponding author

E-mail: parkhs@ulsan.ac.kr

Tel: +82-52-259-1050 Fax: +82-52-221-0152

ORCID: 0000-0002-5523-7633 
the major challenge encountered with most sustainability assessment methods is integrating the three sustainability dimensions (i.e., economy, society, and environment), having disparate units of measurement, into a standard scale [16]. On the one hand, monetary units represent economic data, and social data is available in socio-economic indices. On the other hand, the environmental data could be represented by a variety of units and indices, thus making overall results incompatible with other units or indices. These limitations are effectively addressed by using emergy accounting for sustainability assessments by using a common unit of measurement. This common unit in emergy accounting represents the "available energy of one kind used up directly and indirectly to generate a service or product" [17] and is usually referred to as the solar emergy [18]. The unit for solar emergy is solar emjoule (sej), which is defined as the cumulative amount of available solar energy converging to create a resource, product, or a service $[3,19]$. Based on this definition, emergy provides a donor-side perspective in measuring the "quality" of energy on a macro scale, indicating a hierarchical chain of energy in space and time [20, 21].

In the available literature, emergy accounting approach has been applied to various regions and sectors. Application at the national-levels includes that for United States [22], China [14, 23], Japan [24], Spain [25], Mongolia [26], Taiwan [27], etc. Similarly, emergy analysis at the city-levels [28-31] and smaller islands [32] can also be found. Applications at the sectoral levels are also available for industrial parks [33-35], dairy production systems [20], paper and pulp industry [36], construction [37], etc. Other advantages of using emergy accounting for sustainability assessments are the robustness of results [38] and donor-side perspectives (useful to identify how resource input from the environment could contribute to the economy) [39]. However, there is a lack of studies that were developed for demonstrating the sustainability connection between the past and future for a system based on time-series data. In this regard, System Thinking Experimental Learning Laboratory with Animation (STELLA) is a modeling tool that helps design system models and allows the observation of the behavioral changes of the variables in a complex system. Therefore, this study aims to fill this gap by establishing a hybrid model based on emergy analysis and STELLA modeling tool for sustainability assessment using a retrospective and prospective approach. Moreover, there is no such study employing regression models and STELLA approach for futuristic emergy estimation at the national level, thus, making this research highly informative and intuitive.

With this circumstance, this study investigates a smaller South Asian country, Nepal, using emergy accounting approach. Nepal is a land-locked country with a gross domestic product (GDP) size of 30.6 billion USD and an annual GDP growth rate of $7.0 \%$, as of 2019 [40]. Moreover, the country is facing higher economic turbulence due to natural disasters in the recent years. However, Nepal is still a developing country (per capital GDP of $\sim 1,000$ USD) and future sustainable development is very much interlinked with its economic progress. This study, therefore, also aims to provide policy-level instruments for future sustainable economic development for Nepal and countries alike based on the emergy approach. In general, sustainability status of a country depends on the availability of natural resources, the rate of resource consumption, and resource flows (in the form of trade) to other regions. In this context, countries relying primarily on renewable emergy (as opposed to non-renewable emergy) are considered higher on the sustainability hierarchy with respect to other countries [28, 41]. Put simply, countries achieving the highest yield with the least environmental load are considered relatively "sustainable" [17].

\section{Methodology}

This section describes the overall approach used to quantify different emergy indices.

\subsection{Emergy Analysis}

In the emergy accounting approach, each form of energy flowing into a system is converted into its solar energy equivalent, i.e., solar emergy, by multiplying the inputs and outputs with their respective solar transformity. The larger the transformity, the more solar energy is required to generate a resource, product, or a service, and higher their position in the energy hierarchy of the universe [17, 42]. The emergy accumulation of a system is assessed following as a top-down approach, and this can be generalized in four steps:

(i) Development of the emergy diagram helps to visualize all input and output resource flows within a system. In this study, the administrative boundary of Nepal was considered as the system boundary.

(ii) The emergy table is then constructed to facilitate the system-based resource flow calculations. In this table, data for energy, mass, and monetary flows are multiplied with respective Unit Emergy Values (UEVs) to calculate the emergy flow in seJ. UEVs are the ratio of emergy per unit energy or mass [17]. When UEV is expressed in units of energy, i.e., joules, it is termed as "transformity", however, when expressed in units of mass or money, it is termed as "specific emergy". The values for UEV are based on existing literature $[17,43,44]$.

(iii) The tabulated emergy values are summarized in the form of an emergy summary table. Combining the emergy system diagram and summary table, an aggregated emergy diagram is constructed, which helps visualize the material flows into and within the system.

(iv) Lastly, emergy index table is developed comprising of emergy indices, including emergy yield ratio (EYR), emergy loading ratio (ELR), and emergy sustainability index (ESI). These indicators help understand the economy-wide sustainability trajectories and support in the development of policy-level interventions. Table 1 provides the details of these indices.

The ELR $<2$ indicates relatively low or diluted environmental pressures, ELR in the range 3 10 indicates moderate ecological pressures, while ELR > 10 indicates severe ecological impacts. These environmental pressures are associated with the scale of concentrated non-renewable emergy flows in a local environment [15]. As far as EYR is concerned, the lowest possible value of 
Table 1. List of Emergy Indicators Used in This Study

\begin{tabular}{|c|c|c|}
\hline Notation & Description & Formulae $^{\text {a }}$ \\
\hline ELR - Environmental Loading Ratio & $\begin{array}{l}\text { The ratio of non-renewable (both local and imported) to renewable } \\
\text { use, called the Environmental Loading Ratio (ELR), reflects the } \\
\text { magnitude of the difference between the historic and current local } \\
\text { environmental system in terms of non-renewable resource-use intensity. }\end{array}$ & $\frac{\left(F_{i}+G_{i}+P 2 I\right)+N 0+N 1}{R}$ \\
\hline EYR - Environmental Yield Ratio & $\begin{array}{l}\text { The ratio of the emergy yield to that required for processing. Total } \\
\text { emergy released (used up) per unit of emergy invested. }\end{array}$ & $\frac{U}{\left(F_{i}+G_{i}+P 2 I\right)}$ \\
\hline ESI - Emergy Sustainability Index & $\begin{array}{l}\text { It measures how sustainable a system is. It indicates the openness } \\
\text { and loading changes occurring over time in both technological processes } \\
\text { and economies. }\end{array}$ & $\frac{\text { EYR }}{\text { ELR }}$ \\
\hline
\end{tabular}

\footnotetext{
${ }^{a}$ based on [60] where:

$F_{i}$ equals the sum of imported fuel, metal, and minerals;

$\mathrm{G}_{\mathrm{i}}$ equals the sum of remaining imported materials and electricity;

P21 equals emergy value of services imports [service in imports (\$) * world emergy money ratio (sej/\$)];

No equals the dispersed rural sources such as soil and forest biomass if their storages are being used faster than they are regrowing; $\mathrm{N} 1$ equals concentrated nonrenewable extraction as the sum of fuel, metal, and mineral production minus pass through commodities such as minerals that are mined and exported without further processing;

$\mathrm{R}$ equals renewable sources calculated as the largest terrestrial renewable flow plus the tide; and

$U$ is the total emergy used.
}

1 indicates that a system cannot exploit local resources effectively and that emergy input and output are the same for that system or process [15]. The EYR values greater than 1 indicate their higher contribution to the economy in terms of net emergy. Then comes the sustainability indicator, ESI, whose lowest possible value could be 0 . The ESI values $<1$ indicate consumer-oriented systems, while ESI values $>1$ indicate pre-industrial systems with relatively lower environmental impacts [15].

In this study, the whole country (Nepal) was considered as a "system" and its geographical boundaries as "system boundaries". The resource production and energy flows, such as the local indigenous resources and non-renewable resources which support the system (including import and export of energy, materials, and information) are quantified in solar emergy units.

\subsection{Hybrid Model based on Emergy and STELLA}

The STELLA modelling approach was employed using the available data for 1998-2015 to simulate projected emergy parameters for the year 2015 to 2040. The STELLA method is a computer-run program using iconographic interface to design and construct dynamic systems models comprising stocks, flows, auxiliary variables, and informational flows [45]. By STELLA in this study, a retrospective and prospective emergy analysis was carried out to calculate different emergy indicators including total emergy use, emergy use per capita, import emergy, export emergy, electricity uses per capita, and fuel use per capita. Based on the retrospective data (1998-2015), prospective simulation (for 2015-2040) was performed using STELLA software. To determine auxiliary variables (i.e., mathematical relationships) as an input for STELLA, a regression analysis of the emergy parameters was also conducted. The linear equations thus formed were used in STELLA for prospective prediction of emergy parameters. The regression analysis was done using a Statistical Package for Social Sciences (SPSS). For the regression analysis Eq. (1) was used:

$$
\mathrm{Y}=f(\mathrm{X})
$$

Where $\mathrm{X}$ is an independent variable and $\mathrm{Y}$ is a dependent variable. Regression analysis of individual emergy parameters was done using population/year as the independent variable and the emergy parameters as the dependent variable. Choosing the right regression equation for simulation was done through careful study of probable curve regression models. The curve regression models such as linear logarithmic model, inverse model, quadratic model, growth model, and exponential model were analyzed first by putting the emergy parameter values. Finally, the best regression equation among all the regression models was selected based on higher goodness of fit and the best visual trend observed. The error in predicted versus real value was then estimated by applying Eq. (2):

$$
\mu_{\mathrm{i}}=\mathrm{Y}_{\mathrm{i}}-\overline{\mathrm{Y}}_{\mathrm{i}}
$$

Here, $Y_{i}$ is the actual emergy value and $\bar{Y}_{i}$ is the predicted value calculated by the regression model. The mean predicted error was estimated by using Eq. (3):

$$
\bar{\mu}=\frac{\sum \mu_{\mathrm{i}} \mathrm{f}_{\mathrm{i}}}{\sum \mathrm{f}_{\mathrm{i}}}
$$

Where $\bar{\mu}$ is the mean predicted error, $f_{i}$ is the frequency of the error $\mu_{i}$ The $\bar{\mu}$ was added to $\bar{Y}_{i}$ to calibrate the final result following the method developed by Lei and Wang (2008). After the predicted value was corrected, the final regression equation was applied in STELLA software to make a visual model, and projected emergy values for the 2015-2040 period were estimated. Fig. 1 shows the variables and their relationships used in STELLA model. 


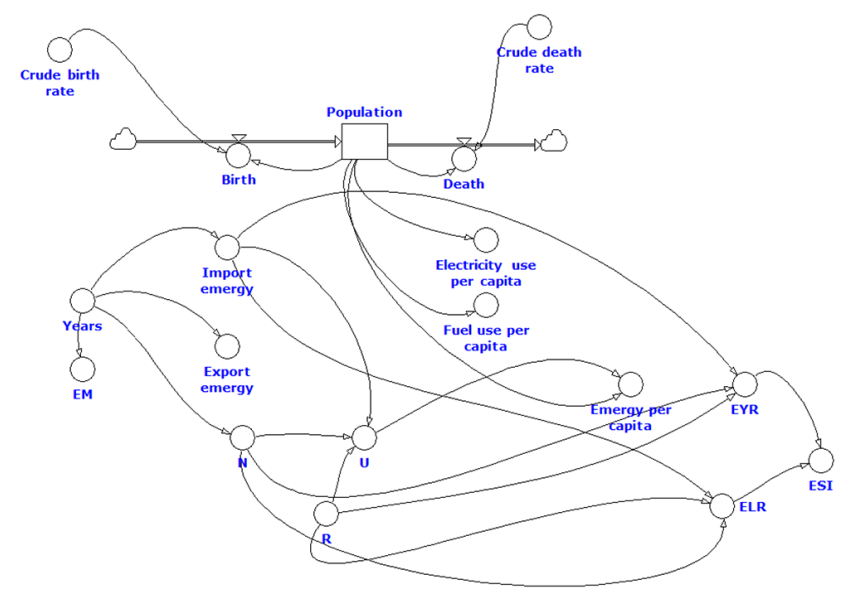

Fig. 1. Variables and their relationships in STELLA.

\subsection{Data Sources}

Multiple data sources have been used in our analysis. The global mineral resource production data was collected from the United States Geological Survey [46]. This data was used to calculate the "world emergy money ratio" which is calculated by dividing the world emergy use (in sej) with the world GDP (in USD). The trade data for emergy analysis after 2007 were collected from the World Integrated Trade Solutions (WTTS) [47]. In this study, annual emergy data from 1998 to 2015 was calculated through the standard emergy method as described in Section 2.1 and Section 2.2. The timeframe from 1998 to 2015 was selected based on data availability and other documented socio-economic events in Nepal (e.g., turbu- lent economic performance, social and political unrest, climatic impacts, etc.). These events are considered to have broader impacts on the overall national economic growth and resource consumption trends [48]. Moreover, this timeframe also helped us analyze Nepal's sustainability indices' influencers before and after the year 2015, using real and projected data, respectively.

\section{Results and Discussions}

\subsection{Retrospective Emergy Accounting of Nepal}

As of 2019, Nepal has a population of about 28.6 million with a land cover of $147,181 \mathrm{~km}^{2}$ and distinct elevation ranges. Nepal has developed a unique ecological belt called the "Terai" in the south Nepal's middle zone is called the "Hills" region ranging from 300 meters to 2,500 meters of elevation. Similarly, the zone above 2,500 meters is called the "High Mountain" zone - popularly known as the "Himalayas" [49]. With a large population and diverse land-use patterns, the national economy is dominated by agriculture, accounting for one-third of the national GDP [50, 51]. The emergy system diagram of Nepal is presented in Fig. 2. This system diagram presents a general overview of resource flows and economic activities in Nepal. The numeric values for each resource flow are classified as renewable resources, indigenous renewable resources, non-renewable resources, and imports and exports are provided in Table S1 and S2 in the supplementary information file. Initial resource flow analysis shows that Nepal's natural resource consumption has increased significantly during 1998-2015 and that the total emergy has increased in a similar pattern with Nepal's GDP, as illustrated in Fig. 3.

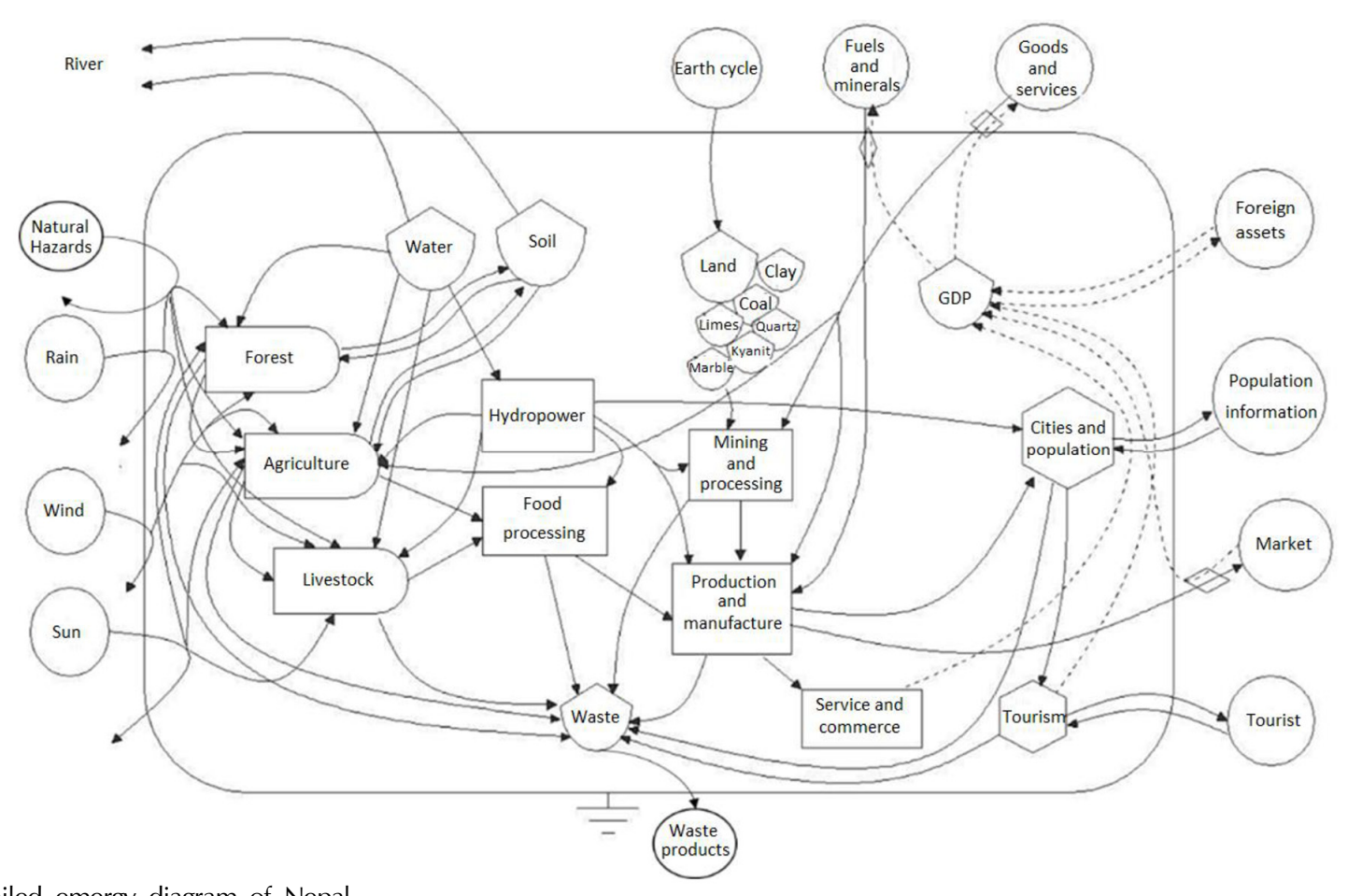

Fig. 2. Detailed emergy diagram of Nepal. 

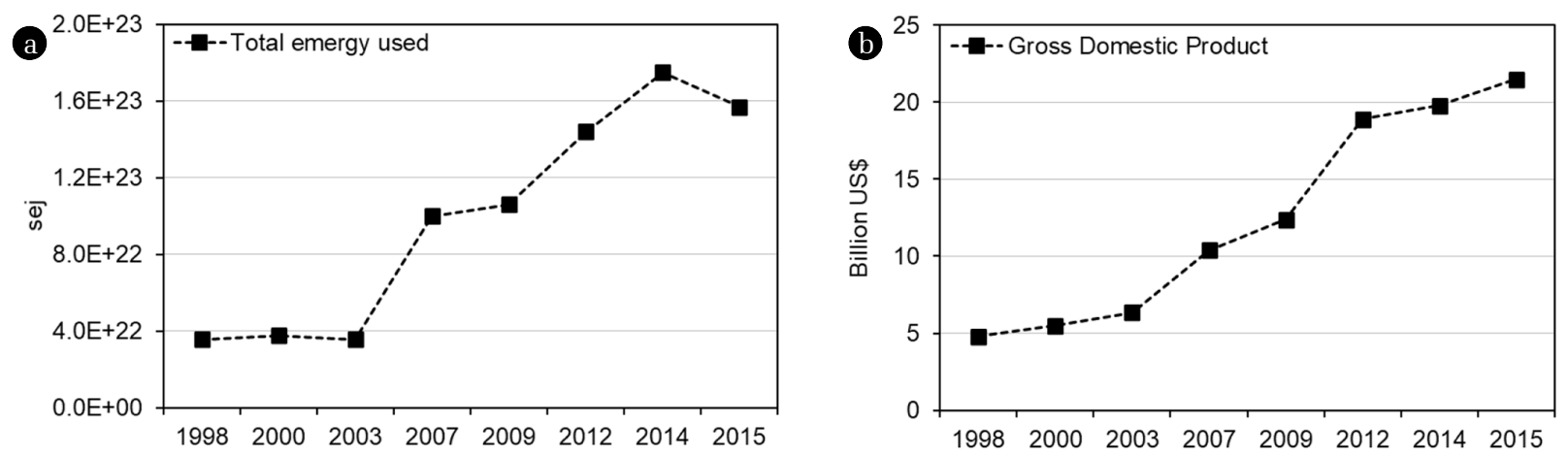

Fig. 3. Showing (a) Nepal's total emergy use and (b) national GDP in current USD prices during 1998-2015.

Nepal's GDP increased from 4.9 billion USD in 1998 to 21.4 billion USD in 2015 (current dollar prices). Similarly, the total emergy use has increased from 3.56E+22 sej in 1998 to $15.7 \mathrm{E}+22$ sej in 2015, an increase by $342.1 \%$. As per the results, GDP growth and total emergy use were slow and steady till the year 2003. Especially after 2007, it grew at a faster pace compared with previous periods. In the pre-2003 scenario, factors slowing down the economy and emergy use were probably influenced by the political instability and security problems arising from the domestic civil war, which eventually ended in 2006. Afterwards, the country's economic and security situation became stable, and the economic development activities in Nepal resumed at a higher speed. Thus, increased economic and urban development drove the rising total emergy use in Nepal during the post-civil war period. However, economic numbers used in this study are based on current US dollar prices and the impact of inflation has not been considered, thus, results should be interpreted accordingly.

Nepal is a highly climate vulnerable country with frequent natural hazards, significant disasters, and varying weather patterns [52]. The most recent natural disaster was the 2015 earthquake in the Gorkha District with a 7.8 magnitude on a Richter scale, resulting in about 9,000 fatalities and above 22,000 injured. Therefore, Nepal is suited as a case study having a relatively smaller economy but with faster recent growth (altering the economic structure and use of imported resources), as well as its geographical position (land-locked with China's Tibet region to North and India to its South), and its potentially high vulnerability to climate change impacts (frequent flash floods and land sliding in recent decades). These factors considered here will help guide policymakers to devise policies which are environmentally sustainable and put minimum pressure on resource consumption based on emergy approach.

\subsubsection{Renewable resources}

Renewable resources (R) are widely categorized into two types, i.e. (i) perpetual resources and (ii) indigenous renewable resources. The perpetual resources are the resources that can be utilized continuously, free of costs, such as solar radiation, rainwater, wind, and geological heat from the earth's crust. In this research, the wind and earth cycles, the two largest contributors, were not considered in total emergy accounting to avoid any double-counting of the resources $[17,53]$. As per the results, the total emergy of perpetual resources calculated for Nepal was equivalent to $2.25 \mathrm{E}+22$ sej.

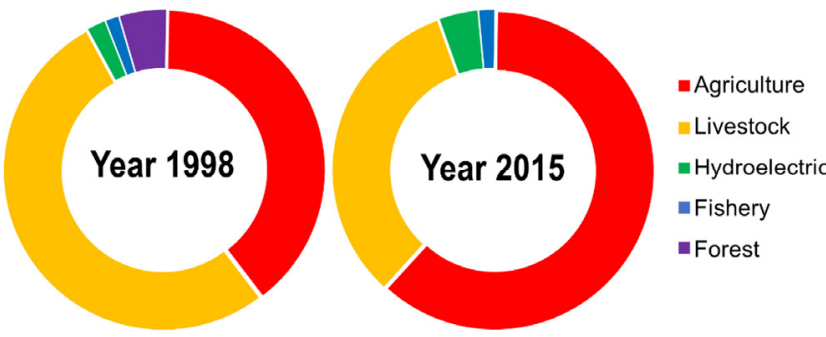

Fig. 4. Share of indigenous resource production in Nepal in 1998 and 2015.

In Nepal, indigenous renewable resource production included agricultural production, livestock production, fishery production, forestry, and hydroelectricity production where agricultural production is the largest indigenous resource production followed by livestock and hydroelectricity generation. In 1998, the emergy of total agricultural production was equal to $1.56 \mathrm{E}+22 \mathrm{sej}$, which further increased to $5.54 \mathrm{E}+22$ sej in 2015. Similarly, the total emergy of livestock production and electricity production was $2.07 \mathrm{E}+22$ sej and 7.78E+20 sej in 1998 while it increased to $2.95 \mathrm{E}+22$ sej and 36.2E+20 sej, respectively, by the end of 2015 .

Looking into the relative contributions of renewable resources (Fig. 4), the share of agricultural production in the total indigenous resources production was $53.4 \%$ in 1998 , which increased to $61.5 \%$ in 2015. Whereas the share of livestock production decreased from $39.4 \%$ in 1998 to $32.7 \%$ in 2015 , which could be attributed to the higher imports from other countries - import of livestock and meat products increased considerably as domestic production reduced. Similarly, with the advent of mega hydro power projects, the share of electricity in indigenous resource production increased from $2.0 \%$ in 1998 to $4.0 \%$ in 2015. Moreover, from 1998 to 2015, the forest production share decreased from $5 \%$ to less than $1 \%$, which highlights Nepal's transition away from biomass-based fuels and towards fossil-based fuels.

\subsubsection{Non-renewable resources}

As per the emergy accounting results, non-renewable resources (N) were categorized into three types: (i) rural resources " $\mathrm{N}_{\mathrm{o}}$ " such as soil, (ii) concentrated resources " $\mathrm{N}_{1}$ " such as metallic and non-metallic minerals, and (iii) non-renewable resources " $\mathrm{N}_{2}$ " such as exported as raw materials. Nepal's local economy is highly 
dependent on agricultural and livestock production; thus, soil erosion is a huge environmental problem in Nepal. In Nepal's hilly terrains, agrarian practices are mostly conventional without proper land management, which causes massive washout of topsoil layers by surface run-off and wind. Similarly, in lower topographic areas such as Terai, the fertile soils are slowly washed away by the flowing rivers. Improper practices in the livestock sector, such as cattle feed using the grassland and forests, also affect the loss of the topsoil layer and its erosion to some extent. The reported annual soil erosion levels in Nepal's agricultural areas and forest lands amounts to nearly 28 and $14 \mathrm{Mt} /$ hectare, respectively [54]. With these major drivers of soil erosion in Nepal, soil loss's total emergy has increased from $1.66 \mathrm{E}+21$ sej in 1998 to $2.64 \mathrm{E}+21$ sej in 2015.

The concentrated non-renewable resource demand includes the demand of metallic minerals, non-metallic minerals and fossil fuels. The total non-renewable resource demand in Nepal increased from $5.83 \mathrm{E}+21$ sej in 1998 to $18.90 \mathrm{E}+21$ sej in 2015 .

The largest quantity of non-renewable resources produced during 1998-2015 was in 2014, totaling to $34.7 \mathrm{E}+21$ sej (about six times higher than that in 1998). The sudden decrease in resource production after 2014 was due to the Gorkha earthquake, causing a halt in mining activities, which ultimately reduced local production. As far as the extraction of non-metallic minerals (e.g., clay, kyanite, limestone, tourmaline, talk, marble, and quartz) is concerned, it is abundantly carried out in Nepal. Some low-grade fossil fuels, such as sub-bituminous coal, are also extracted - about 1.19E+03 million tons in 2015 [55]. To this date, the extraction of high-value metallic minerals such as iron, nickel, gold, silver, zinc, etc., is not done even though their presence has been identified in some regions $[56,57]$. The scarcity of domestic material and petroleum extraction has increased imports from other countries (India being the largest exporter of petroleum fuels and minerals to Nepal) [58]. The non-metallic minerals extracted are domestically consumed without their export; thus, " $\mathrm{N}_{2}$ " was excluded from the total emergy calculation.

\subsubsection{Imports and exports}

The import of natural resources was substantially higher than export, thus, creating a trade deficit in Nepal. As per the results, from 1998 to 2015, the import increased from $7.60 \mathrm{E}+21$ sej to $116.21 \mathrm{E}+21$ sej, while exports increased only from $9.10 \mathrm{E}+21$ sej to $16.20 \mathrm{E}+21 \mathrm{sej}$. Until 2003 , however, the growth trend of imports and exports was similar, indicating a somewhat balanced trade. However, in the post-2003 scenario, the trade pattern has shifted as imports sharply increased, and the exports grew slowly. As of 2015, both the imports and exports were affected mainly due to Gorkha earthquake. Among the imported resources and products, agricultural products, meat, fish, metallic and non-metallic minerals, transportation and mechanical equipment, and finished products had a majority share. Specifically, meat and fish products accounted for the largest emergy share among all the imported resources, which increased from $2.78 \mathrm{E}+19$ sej in 1998 to $5.44 \mathrm{E}+22$ sej in 2015 . This was followed by metals with an emergy value of $217.01 \mathrm{E}+20$ sej in 2015 instead of $2.36 \mathrm{E}+20$ sej in 1998.

In $2014,1.45 \mathrm{E}+22$ sej livestock and fishery products were ex- ported (42\% share in total exports from Nepal). During the same year, all services and finished products were equal to $8.01 \mathrm{E}+21$ sej and 3.57E+21 sej, respectively. However, soon after the earthquake hit Nepal in 2015, the exports sharply fell, producing a robust economic shock to the national economy. As far as tourism is concerned, it is considered an important financial sector in Nepal. In emergy accounting, tourism is usually classified under exports - as incoming tourists use/bring foreign currencies to purchase local goods and services [14]. Interestingly, in Nepal, the tourism industry's income has increased from $1.13 \mathrm{E}+21$ sej in 1998 to $3.96 \mathrm{E}+21$ sej in 2015 , accounting for about $25 \%$ of the total exports in 2015.

\subsection{Sustainability Assessment}

\subsubsection{ELR and EYR}

The environmental loading ratio, i.e., ELR, is the ratio of non-renewable emergy use (both local and imported) to the renewable emergy use. It measures the pressure on environment from economic activities including resource intensification [59] in terms of non-renewable and renewable emergy. The environmental yield ratio, i.e., EYR, is the total emergy consumed per unit of emergy invested. Fig. 5 (a) illustrates the ELR and EYR of Nepal during 1998-2015. The EYR also helps in analyzing how efficiently a system is utilizing locally available natural resources.

The correlation between EYR and ELR also helps in evaluating the environmental sustainability as systems (or region) with a higher EYR and a lower ELR may be considered economically and environ
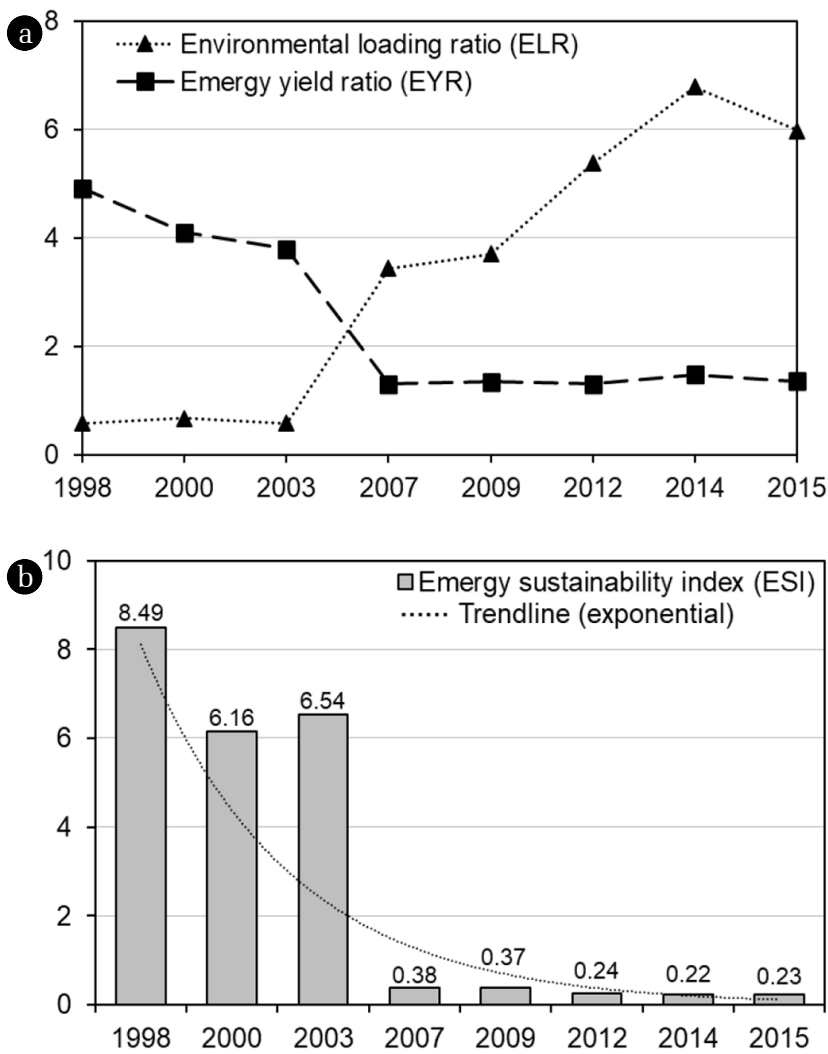

Fig 5. Changes in (a) ELR and EYR, and (b) ESI, in Nepal during 1998-2015. 
mentally sustainable [31]. As per the results, the EYR of Nepal was 4.7 in 1998 as most of the resources were produced and transformed locally, which supported the economy while keeping the imports low. Nevertheless, after 2007, the EYR value reached 1.4, indicating a decreased use of local resources and increased imports. During 2007-2015, Nepal's ELR had risen from 3.4 in 2007 to 6.0 in 2015, mostly due to increased imports and consumption of fossil fuels and metallic minerals [58]. Detailed data showing summary of emergy indices is provided in Table S3 in the supplementary information file.

\subsubsection{Environmental Sustainability Index (ESI)}

The environmental sustainability index, or ESI, is an emergy-based indicator for national-level progress in decoupling environmental impact from economic growth. Mathematically, ESI index is the ratio of EYR and ELR. A country with ESI lower than 1 is indicative of highly developed consumer-oriented with heavy reliance on imports for resource fulfillment, those with ESI between 1 10 could be termed as developing economies, and those with ESI higher than 10 could be categorized as least-developed agricultural economies [15]. In Nepal's case, before 2003, ESI was $>6$, but after 2007, it went below 1 . This trend can be explained as in the pre-2003 situation, the share of renewables in total emergy use was high, and the imports of non-renewable resources were low. Thus, the environmental load was low, and the economy was relatively less industrialized and more sustainable. After 2007, the contribution of renewable use decreased, and imports of non-renewable resources increased, causing the ELR to increase, consequently reducing the ESI. After 2007, Nepal's economic outlook made a transition towards a consumer-oriented economy as reliance on imported resources was higher than ever. Fig. 5(b) presents the ESI for Nepal during 1998-2015.

To verify the robustness of our results, we have compared ESI numbers from this study with those published by the National

Table 2. Comparison of Indices from NEAD and This Study for 2000

\begin{tabular}{lccc}
\hline Emergy indices & $\begin{array}{c}\text { NEAD } \\
(\mathbf{2 0 0 1})\end{array}$ & $\begin{array}{c}\text { NEAD } \\
\mathbf{( 2 0 1 4 )}\end{array}$ & $\begin{array}{c}\text { This study } \\
\mathbf{( 2 0 0 0 )}\end{array}$ \\
\hline EYR & 4.13 & 1.60 & 4.10 \\
ELR & 0.83 & 5.99 & 0.67 \\
ESI & 4.96 & 0.267 & 6.13 \\
\hline
\end{tabular}

Environmental Accounting Database (NEAD). NEAD is an automated emergy accounting platform covering ecological data for several countries, including Nepal, with global energy, material, and monetary flows. According to the developers of NEAD, more than 30 global data sources are used for calculating NEAD indices in the latest 2017 version covering 213 countries/regions around the world for the period from 2000 to 2014. The NEAD database includes environmental flows (sunlight, rainfall), natural capital stocks (soil, water, forests, fish), mined materials (metals, fuels) and economically transformed goods and services (agricultural commodities, manufactured goods, services) [44, 60]. Using the NEAD emergy indices for the year 2001 and 2014, a comparison with this study is presented in Table 2. As shown in Table 2, the ESI values from this study are higher than those from the NEAD database, while EYR and ELR are lower than those reported by NEAD. There could be several reasons for these deviations. First, the emergy indices are based on the flows of renewable and non-renewable resources, import and export of raw minerals, agricultural products, fibers, equipment and machinery, labor and services, exchange of money, etc., relative to a system, for example a country. As the global data is mostly available in monetary values and has been utilized by the NEAD database, accuracy may be questionable, as for a complete emergy assessment, the real data developed and maintained by government-run institutions is considered essential and the emergy evaluation through monetary transactions may significantly cause deviation in results. Second, the transformity values used in emergy accounting also affect the resultant indices and could be the source of variations in their final numbers. Nonetheless, the NEAD database results could still be a good starting point and utilized as a baseline to develop future research directions and policy-level interventions both at a regional and national scale.

\subsection{Prospective Emergy Predication}

Based on the emergy parameters calculated for the 1998-2015 period, simulation of those parameters has been done for the next 25 years. By using population as an independent variable [61], nine different regression curve models are developed as provided in Table S4 in the supplementary information file. Based on the criteria, the logarithmic model was selected for further analysis and simulation. To verify that the predicted values resemble with the real values,

Table 3. Emergy Values and Indices for 1998, 2015, and 2040

\begin{tabular}{ccccc}
\hline Items & $\mathbf{1 9 9 8}$ & $\mathbf{2 0 1 5}$ & $\mathbf{2 0 4 0}$ & Ratio $^{\mathbf{a}}$ \\
\hline Population & $2.21 \mathrm{E}+07$ & $2.80 \mathrm{E}+07$ & $4.07 \mathrm{E}+07$ & 1.45 \\
Export emergy (sej/y) & $9.00 \mathrm{E}+21$ & $1.62 \mathrm{E}+22$ & $1.57 \mathrm{E}+23$ & 9.71 \\
Import emergy (sej/y) & $7.24 \mathrm{E}+21$ & $1.16 \mathrm{E}+23$ & $3.09 \mathrm{E}+23$ & 2.66 \\
Non-renewable emergy (sej/y) & $5.83 \mathrm{E}+21$ & $1.89 \mathrm{E}+22$ & $2.56 \mathrm{E}+23$ & 13.52 \\
Total emergy (U) (sej/y) & $3.56 \mathrm{E}+22$ & $1.57 \mathrm{E}+23$ & $1.97 \mathrm{E}+23$ & 3.73 \\
EYR & 4.92 & 1.36 & 25.10 & 1.40 \\
ELR & 0.58 & 5.98 & 0.1 & 0.33 \\
ESI & 8.49 & 0.23 & & 0.19
\end{tabular}

\footnotetext{
${ }^{a}$ The last column shows the ratio of 2040 values divided by the 2015 values.
} 
two-tailed t-test was performed between the actual value and the projected value. The result shows that the actual values were not significantly different from predicted values $(\mathrm{P}=0.736$; two-tailed t-test). This shows that the logarithmic model provides realistic and accurate projections. Table 3 lists the actual and predicted emergy values and indices for 2015 and 2040.

With the population of Nepal as 4.07E+7 in 2040, as per the calculations, the total emergy use (U) will increase 5 times to $5.87 \mathrm{E}+23$ sej. This will also increase per capita emergy use. The per capita emergy use will reach $1.44 \mathrm{E}+16$ sej in 2040 . The extraction of non-renewable resources will increase 14 fold from 2015. The trade results show that the exports will grow about ten times and imports will grow 2.6 times.

Moreover, the EYR will increase to 1.90 in 2040 with an expected increase in economic activities; however, this will also lead to increased environmental load. The ELR is projected to grow significantly by 2040 . Similarly, the ESI will decrease to the lowest, 0.10. This suggests that Nepal's resource production and consumption in the coming years might intensify, thus increasing the probability of environmental problems if adequate policies are not devised.

\subsection{Implications}

From the results of this study, to mitigate the environmental burden from non-renewable resources, sustained economic growth with improved social wellbeing should be the primary motivation for future policies to promote domestic extraction of non-renewable resources, reduce imports of non-renewable resources, increase renewable resource consumption, control the trade deficit, export finished goods and services, and value addition of domestic raw minerals. As per our findings, Nepal's trade imbalance is high, where the trade ratio (import to export) has reached 7:1 in 2015. The in-depth comparison of national with global emergy values and indices could support national policies and priorities. Also, the earthquake in 2015 played a key role in decreasing exports, thus, calling for more systematic policies towards minimizing trade deficit and boosting local industries, including tourism.

Another vital concern for Nepal is the emergy of soil loss, which indicated erosion has increased in Nepal, especially during the last few years. The soil erosion acts as a double-edged sword that degrades soil fertility (producing no benefit for the national economy) while increasing the demand for chemical fertilizers for agricultural production. In 2010 alone, 0.4 million metric tons of chemical fertilizers were imported in Nepal for agricultural consumption - a significant burden on the national exchequer [62]. Therefore, soil erosion's hidden costs could be taken into consideration when short- and long-term policy interventions are developed or executed. The control of soil erosion could increase the EYR of the country to improve the sustainability score.

Lastly, renewable energy resources such as solar, wind, wave, geothermal, etc., are widely known as cleaner energy resources with less environmental impacts. Thus, replacing conventional energy resources with renewable energy technologies could mitigate environmental degradation and greenhouse gas emissions. As countries with higher renewable energy share are considered more sustainable in the long run $[14,63]$, the share of renewable resources in Nepal, unfortunately, decreased sharply from 63\% in 1998 to
14\% in 2015. This trend of lower EYR and higher ELR has been reported for other countries where they tend to rely on large quantities of non-renewable emergy and higher imported total emergy use [63]. For example, ESI for several developed countries is less than 1 including United States (0.48) [17], Italy (0.17) [64], Taiwan (0.16) [65], etc. Moreover, a decreasing share of renewables results in an increased ELR simultaneously; therefore, Nepal should begin the transition towards renewable energy resources to meet the national demands. The incentives through policy tools could encourage the use of renewable resources/technologies within the country. In this regard, we also recommend the use of other indices such as foreign aid, foreign direct investment, etc., in future emergy-based studies.

In addition, certain limitations also apply to this work. First, results based on STELLA approach should be compared with those from others emergy methods so that a comparative analysis could be performed and high robustness of results could be achieved [66]. Also, the data used in this study was up to the year 2015, whereas significant changes in annual emergy flows could be found. Therefore, variations in our results could be expected with more recent data. The use of emergy indices also need some level of standardization such that interpretation becomes convenient with other metrics such as those based on regional input-output tables and mass flow accounts.

\section{Conclusions}

This study investigated Nepal's economic and environmental sustainability using the emergy accounting approach for 1998-2015 (real data, retrospective) and 2015-2040 (projected data, prospective). The results showed that Nepal's economy has improved during the study period while its total emergy use has increased from $3.60 \mathrm{E}+22$ sej in 1998 to $15.70 \mathrm{E}+23$ sej in 2015, showing a 44 -fold increase in a 17-year timeframe. Trends in imports and exports showed increasing numbers until 2007 when imports exceeded exports, thus resulting in negative trade balance. In 1998, emergy sustainability index (ESI) was 8.5 with higher emergy yield ratio and lower environmental loading. However, in 2015, ESI was reduced to 0.23 with lower emergy yield ratio and increased environmental loading - indicating more consumerism, poor resource sustainability, and higher reliance on non-renewable resources. This trend of reducing ESI is similar to many developing economies though it comes at the expense of increased consumption of non-renewable resources. The analysis for 2015-2040 showed that ESI could be further reduced and non-renewable emergy could rise considerably - indicating forthcoming pressure on the natural capital and the environment.

\section{Acknowledgments}

This work was supported by Brain Korea 21plus (BK-21 plus) program from the Ministry of Education, Science, and Technology, and Basic Research Program of the National Research Foundation of Korea (NRF) was provided by the Ministry of Education (NRF2020R1I1A2072313). 


\section{Author Contributions}

K.S. (M.Sc. student) took part in conceptualization, methodology, and software. I.H.S. (Research Associate) contributed to software analysis, data curation, modeling, and draft preparation. Z.L. (Professor) contributed to writing, review, editing, and H.-S.P. (Professor) took part in supervision, project administration, and reviewing.

\section{References}

1. Campbell DE, Williams SL. Environmental accounting using emergy evaluation of the state of West Virgina; 2005 [cited 20 September 2019]. Available from: https://nepis.epa.gov/ Exe/ZyNET.exe/.

2. Waas T, Hugé J, Block T, et al. Sustainability Assessment and Indicators: Tools in a decision-making strategy for sustainable development. Sustainability 2014;6:5512-5534.

3. Santagata R, Viglia S, Fiorentino G, et al. Power generation from slaughterhouse waste materials. An emergy accounting assessment. J. Clean. Prod. 2019;223:536-552.

4. Shah IH, Park H-S. Chronological change of resource metabolism and decarbonization patterns in Pakistan: Perspectives from a typical developing country. J. Ind. Ecol. 2020;1-18.

5. Rama M, González-García S, Andrade E, et al. Assessing the sustainability dimension at local scale: Case study of Spanish cities. Ecol. Indic. 2020;117:106687.

6. Campbell DE, Garmestani AS. An energy systems view of sustainability: Emergy evaluation of the San Luis Basin, Colorado. J. Environ. Manage 2012;95:72-97.

7. Elkington J. Towards the Sustainable Corporation: Win-Win-Win Business Strategies for Sustainable Development. Calif Manage Rev. 1994;36:90-100.

8. Shah IH, Dong L, Park H-S. Tracking urban sustainability transition: An eco-efficiency analysis on eco-industrial development in Ulsan, Korea. J. Clean. Prod. 2020;262:121286.

9. González-Mejía AM, Ma X (Cissy). The emergy perspective of sustainable trends in puerto rico from 1960 to 2013. Ecol. Econ. 2017;133:11-22.

10. United Nations. Transforming our world: The 2030 Agenda for Sustainable Development; 2015 [cited 20 September 2018]. Available from: https://sustainabledevelopment.un.org/content/documents/21252030.

11. Onat NC, Aboushaqrah NNM, Kucukvar M, et al. From sustainability assessment to sustainability management for policy development: The case for electric vehicles. Energy Convers Manag. 2020;216:112937.

12. Shah IH, Dong L, Park HS. Characterization of resource consumption and efficiency trends in Bangladesh, India and Pakistan: Economy-wide biotic and abiotic material flow accounting from 1978 to 2017. J. Clean. Prod. 2020;250:119-136.

13. Patterson M, McDonald G, Hardy D. Is there more in common than we think? Convergence of ecological footprinting, emergy analysis, life cycle assessment and other methods of environmental accounting. Ecol. Modell. 2017;362:19-36.

14. Jiang MM, Zhou JB, Chen B, et al. Emergy-based ecological account for the Chinese economy in 2004. Commun. Nonlinear Sci. Numer Simul. 2008;13:2337-2356.

15. Brown MT, Ulgiati S. Emergy analysis and environmental accounting. Encycl. Energy 2004;2:329-354.

16. Gasparatos A, El-Haram M, Horner M. The argument against a reductionist approach for measuring sustainable development performance and the need for methodological pluralism. Account. Forum 2009;33:245-256.

17. Odum HT. Environmental accounting: Emergy and environmental decision making. Wiley; 1996 [cited 25 September 2019]. Available from: https://www.wiley.com/en-us/.

18. Liu Z, Geng Y, Ulgiati S, et al. Uncovering key factors influencing one industrial park's sustainability: A combined evaluation method of emergy analysis and index decomposition analysis. J. Clean. Prod. 2016;114:141-149.

19. Asgharipour MR, Amiri Z, Campbell DE. Evaluation of the sustainability of four greenhouse vegetable production ecosystems based on an analysis of emergy and social characteristics. Ecol. Modell. 2020;424:109021.

20. Agostinho F, Oliveira MW, Pulselli FM, et al. Emergy accounting as a support for a strategic planning towards a regional sustainable milk production. Agric. Syst. 2019;176:102647.

21. Tilley DR. Exploration of Odum's dynamic emergy accounting rules for suggested refinements. Ecol. Modell. 2014;279:36-44.

22. Tilley DR. National Metabolism and Communications Technology Development in the United States, 1790-2000. Environ. Hist Camb. 2006;12:165-190.

23. Yang ZF, Jiang MM, Chen B, et al. Solar emergy evaluation for Chinese economy. Energy Policy 2010;38:875-886.

24. Gasparatos A, Gadda T. Environmental support, energy security and economic growth in Japan. Energy Policy 2009;37:40384048.

25. Lomas PL, Álvarez S, Rodríguez M, et al. Environmental accounting as a management tool in the Mediterranean context: The Spanish economy during the last 20 years. J. Environ. Manage 2008;88:326-347.

26. Li H, Brown M. Emergy-based environmental accounting toward a sustainable Mongolia. J. Geogr. Sci. 2017;27:1227-1248.

27. Huang S-L, Lee C-L, Chen C-W. Socioeconomic metabolism in Taiwan: Emergy synthesis versus material flow analysis. Resour. Conserv. Recycl. 2006;48:166-196.

28. Campbell DE. Emergy Analysis of Human Carrying Capacity and Regional Sustainability: An Example Using the State of Maine. Environ. Monit. Assess 1998;51:531-569.

29. Lei K, Wang Z. Emergy synthesis and simulation for Macao. Energy 2008;33:613-625.

30. Zhang Y, Yang Z, Liu G, et al. Emergy analysis of the urban metabolism of Beijing. Ecol. Modell. 2011;222:2377-2384.

31. Zhu LP, Li HT, Bouldin J, et al. Emergy-based environmental accounting: Evaluation of Inner Mongolia Autonomous Region. Acta. Ecol. Sin. 2012;32:74-88.

32. Nam J, Chang W, Kang D. Carrying capacity of an uninhabited island off the southwestern coast of Korea. Ecol. Modell. 2010;221:2102-2107.

33. Geng Y, Liu Z, Xue B, et al. Emergy-based assessment on industrial symbiosis: a case of Shenyang Economic and Technological Development Zone. Environ. Sci. Pollut. Res. 
2014;21:13572-13587.

34. Geng Y, Zhang P, Ulgiati S, et al. Emergy analysis of an industrial park: The case of Dalian, China. Sci. Total Environ. 2010;408: 5273-5283.

35. Zhe L, Yong G, Hung-Suck P, et al. An emergy-based hybrid method for assessing industrial symbiosis of an industrial park. J. Clean. Prod. 2016;114:132-140.

36. Santagata R, Zucaro A, Fiorentino G, et al. Developing a procedure for the integration of Life Cycle Assessment and Emergy Accounting approaches. The Amalfi paper case study. Ecol. Indic. 2020;117:106676.

37. Giannetti BF, Demétrio JCC, Agostinho F, et al. Towards more sustainable social housing projects: Recognizing the importance of using local resources. Build. Environ. 2018;127:187-203.

38. Giannetti BF, Almeida CMVB, Agostinho F, et al. Primary Evidences on the Robustness of Environmental Accounting from Emergy. J. Environ. Account. Manag. 2013;1:203-212.

39. Tian X, Sarkis J. Expanding green supply chain performance measurement through emergy accounting and analysis. Int. J. Prod. Econ. 2020;225:107576.

40. World Bank. World Development Indicators. National accounts data, and OECD national accounts data files. The World Bank; 2020 [cited 20 September 2020]. Available from: https://data. worldbank.org.

41. Brown MT, Ulgiati S. Emergy evaluation of the biosphere and natural capital. Ambio 1999;486-493.

42. Tilley DR. Dynamic accounting of emergy cycling. Ecol. Modell. 2011;222:3734-3742.

43. Kang D. Emergy evaluation of the Korean economy and environment: Implications for the valuation of marine ecosystem services. J. Korean Soc. Mar. Environ. Energy 2015;18:102-115.

44. NEAD. NEAD Data by Indices: National Environmental Accounting Database; 2012 [cited 10 September 2021]. Available from: https://www.cep.ees.ufl.edu/nead/data.

45. Costanza R, Voinov A. Modeling ecological and economic systems with STELLA: Part III. Ecological Modelling 2001;143:1-7.

46. USGS. Mineral Commodity Summaries: National Minerals Information Center. United States Geological Survey; 2018 [cited 20 September 2018]. Available from: https://www.usgs. org/Default.aspx?lang=en.

47. World Bank. World Integrated Trade Solution (WITS): Access and retrieve information on trade and tariffs. The World Bank; 2018 [cited 25 September 2018]. Available from: https://wits. worldbank.org/Default.aspx?lang=en.

48. Einsiedel VS, Salih C. Conflict Prevention in Nepal: Background Paper for the United Nations World Bank Study on Conflict Prevention; 2018 [cited 20 September 2018]. Available from: https://www.alnap.org/help-library/conflict-prevention-innepal-background-paper-for-the-united-nations-world-bankstudy.

49. Government of Nepal. Study of climate and climatic variation over Nepal; 2015 [cited 20 September 2018]. Available from: http://www.dhm.gov.np/uploads/climatic/.

50. Central Bureau of Statistics. National Planning Commission Secretariat, Government of Nepal, 2015 [cited 20 September 2018]. Available from: http://www.cbs.gov.np/.

51. CIA. The World Fact-book - Nepal Economy 2017. Central
Intelligence Agency; 2017 [cited 20 September 2018]. Available from: https://www.cia.gov/library/publications/the-world-factbook/geos/np.html.

52. CFE-DMHA. Center for excellence in disaster management \& humanitarian assistance. Nepal: Disaster management reference handbook; 2017 [cited 20 September 2018]. Available from: https://reliefweb.int/sites/reliefweb.int/files/resources/CFEDM.pdf.

53. Brown MT, Ulgiati S. Energy quality, emergy, and transformity: H.T. Odum's contributions to quantifying and understanding systems. Ecol. Modell. 2004;178:201-213.

54. Shrestha DP. Assessment of Soil Erosion in the Nepalese Himalaya, A Case Study in Likhu Khola Valley, Middle Mountain Region. L Husb 1997;2:59-80.

55. MoF. Economic Survey, Ministry of Finance, Government of Nepal. Economic Survey 2015-2016; 2017 [cited 20 September 2018]. Available from: http://mof.gov.np/en/archive-documents/economic-survey-21.html.

56. IBN. Mines and Minerals Sector Profile: Investment Board Nepal; 2017 [cited 20 September 2018]. Available from: http://www.ibn. gov.np/.

57. Int'l Business Publications USA. Nepal Mineral \& Mining Sector Investment and Business Guide. Int'l Business Publications USA; 2013.

58. NOC. Nepal Oil Corporation. Nepal oil corporation, Government of Nepal; 2015 [cited 17 June 2017]. Available from: http://www. nepaloil.com.np/.

59. UNEP. Environmental Accounting of National Economic Systems: An Analysis of West African Dryland Countries within a Global Context. Nairobi, Kenya; 2012 [cited 15 September 2018]. Available from: https://wedocs.unep.org/bitstream/ handle/20.500.11822/9510.

60. NEAD. NEAD Data by Indices: National Environmental Accounting Database 2012 [cited 10 September 2018]. Available from: http://www.cep.ees.ufl.edu/nead/data.

61. GON. Nepal population report 2016. Singha Durbar, Kathmandu: Government of Nepal, Ministry of Population and Environment(MOPE); 2016

62. Takeshima H, Adhikari RP, Kaphle BD, et al. Determinants of chemical fertilizer use in Nepal 2016 [cited 20 September 2018]. Available from: http://www.ifpri.org/publication/determinants-chemical-fertilizer-use-nepal-insights-based-priceresponsiveness.

63. Brown M, Ulgiati S. Emergy-based indices and ratios to evaluate sustainability: monitoring economies and technology toward environmentally sound innovation. Ecol. Eng. 1997;9:51-69.

64. Ulgiati S, Bastianoni S, Nobili L, et al. A thermodynamic assessment of biodiesel production from oil seed crops: energy analysis and environmental loading. In: 27th ISATA Conference on Electric, Hybrid and Alternative Fuel Vehicles and Supercars. U.K. Automotive Automation Limited; 1994. p. 477-489.

65. Huang S, Shih TH. The evolution and prospects of Taiwan's ecological economic system. Chinese Regional Science Association 1992.

66. Shrestha K, Shah IH, Liu Z, Park HS. Efficiency assessment in co-production systems based on modified emergy accounting approach. Ecol. Indic. 2021;126:107675. 